\title{
The impact of body size changes on recurrence risk depends on age and estrogen receptor status in primary breast cancer
}

\author{
Helga Tryggvadottir ${ }^{1} \cdot$ Maria Ygland Rödström $^{1} \cdot$ Andrea Markkula $^{1} \cdot$ Xuyian Kenéz ${ }^{1} \cdot$ Karolin Isaksson $^{2}$. \\ Signe Borgquist ${ }^{1,3} \cdot$ Helena Jernström ${ }^{1}$
}

Received: 10 April 2019 / Accepted: 30 August 2019 / Published online: 12 September 2019

(c) The Author(s) 2019

\begin{abstract}
Purpose To investigate the prognostic impact of body size changes during the first postoperative year in breast cancer.

Methods A cohort of 1,317 primary breast cancer patients included in Sweden (2002-2014) underwent body size measurements at the preoperative and 1-year visits $(n=1,178)$. Landmark survival analyses were used to investigate how postoperative weight gain or loss $(>5 \%)$ or change in waist-hip ratio (WHR) categories $(\leq 0.85$ or $>0.85)$ impact prognosis.

Results Median age at inclusion was 61 years and body mass index $25.1 \mathrm{~kg} / \mathrm{m}^{2}$. After a median follow-up of 5.0 years from inclusion, 165 recurrences and 77 deaths occurred. Weight gain (17.0\%) conferred over twofold recurrence risk only in patients $<50$ years $\left(P_{\text {interaction }}=0.033\right)$. Weight loss $(8.6 \%)$ was only associated with a poor prognosis in patients $\geq 70$ years, but not after restriction analysis. Weight change did not impact prognosis in patients 50 to $<70$ years. Changes between WHR categories were associated with differential recurrence risk depending on estrogen receptor $(\mathrm{ER})$ status $\left(P_{\text {interaction }}=0.007\right)$, with higher recurrence risk in patients with ER+ tumors and lower recurrence risk with ER- tumors.

Conclusion Both changes in terms of weight and WHR category yielded independent prognostic information. Further research is imperative before recommending weight loss for all overweight breast cancer patients.
\end{abstract}

Keywords Breast cancer $\cdot$ Prognosis $\cdot$ Weight gain $\cdot$ Weight loss $\cdot$ Waist-hip ratio change $\cdot$ ABSI

\section{Introduction}

The survival of breast cancer patients has improved during the last decades due to advances in diagnostics and treatments [1,2]. Concurrently, an obesity epidemic has emerged worldwide, which negatively impacts both breast cancer risk and recurrence $[3,4]$. Preoperative body sizes increased significantly 2002-2016 with a negative prognostic impact [5]. Weight change has been investigated in multiple studies, but the impact on breast cancer prognosis remains unclear

Helena Jernström

Helena.Jernstrom@med.lu.se

1 Division of Oncology and Pathology, Department of Clinical Sciences, Lund, Lund University, Barngatan 4, 22185 Lund, Sweden

2 Division of Surgery, Department of Clinical Sciences, Lund, Lund University and Skåne University Hospital, Lund, Sweden

3 Department of Oncology, Aarhus University Hospital, Aarhus University, Aarhus, Denmark
[6-19]. Yet, overweight breast cancer patients in Sweden are often recommended to lose weight.

Weight change following breast cancer diagnosis and treatment is common but might differ according to patients' age and treatments [6, 20-22]. A possible U-shaped relationship with increased risk for both weight gain and loss has been suggested $[7,9,12,15,16,18]$. Adipose tissue is biologically active, and multiple pro-carcinogenic processes associated with weight gain have been identified [3]. Less is known about the mechanisms behind the poor breast cancer prognosis associated with weight loss in observational studies $[6,7,9,11,12,15,16,18]$.

Central obesity is associated with metabolic syndrome [23], altered estrogen/testosterone ratio [24], overall mortality [25], and cancer survival [26]. Central obesity in breast cancer patients has been linked to all-cause and breast cancer-specific mortality [27], but associations might differ between ethnic groups [28].

Waist-hip ratio (WHR) can be used as surrogate measure of central obesity [29]. Recently, the anthropometric index 'a body shape index' (ABSI) was introduced, which is based 
on waist circumference (WC) adjusted for body mass index (BMI) and height [30]. Higher ABSI was associated with mortality risk in the general population [30-33], but breast cancer recurrence and death due to other causes involve different pathways. The prognostic impact of ABSI in breast cancer is unknown.

We hypothesized that a stable body constitution during the first postoperative year after diagnosis would be associated with a favorable prognosis, but that associations might differ between subgroups of patients. The study aimed to investigate the prognostic impact of anthropometric changes from the preoperative visit to the 1-year postoperative visit in breast cancer patients.

\section{Methods}

Primary breast cancer patients assessed preoperatively since October 2002 at the Skåne University Hospital in Lund were asked to join a prospective cohort study regarding lifestyle factors, as previously described [5]. The preoperative visit typically took place a few weeks after diagnosis. The study was approved by the Lund University Ethics Committee (LU75-02, LU37-08, LU658-09, LU58-12, LU37912, LU227-13, LU227-15, and LU458-15), and written informed consents were collected from all participants. By 31 December 2014, 1,578 patients were included in the cohort of whom 1,317 were included in the present study, after exclusion of patients without recorded weight or height, with carcinoma in situ, any preoperative treatment, or early metastases $<0.3$ years. The associations between changes in anthropometric measures and prognosis were analyzed in 1,178 patients who were recurrence-free and had a 1-year visit with measured weight $0.9-1.5$ years from inclusion (Fig. 1).

Patient characteristics, including weight, height, and waist and hip circumference, were measured by trained research nurses at the preoperative visit. These variables, with the exception for height, were measured once more at the 1-year visit. WC was measured at the umbilicus, and hip circumference was measured at the widest part between the hip and the major trochanter. The patients were also asked to complete a questionnaire, as previously described [34].

Tumor characteristics were obtained from each patient's pathology report, regarding invasive tumor size, axillary nodal involvement, histological grade, estrogen receptor (ER), and progesterone receptor (PR) status. All tumors were analyzed at the Department of Pathology at Skåne University Hospital in Lund as previously described [34, 35]. Tumors with $>10 \%$ positive nuclear staining were considered receptor positive.

Adjuvant treatments, including chemotherapy, radiotherapy, tamoxifen, and aromatase inhibitors (AIs), were prescribed according to standard of care. Treatment and additional clinical data, recurrences, and new breast cancers were collected from patient charts and follow-up questionnaires. Only breast cancer treatment before any breast cancer event was considered in the analyses. Date of death was obtained from the Swedish population registry. Data on events and new cancers were also collected from the regional tumor registry, which is close to $100 \%$ complete.

\section{Statistical analyses}

Statistical analyses were performed with the software SPSS 24.0 (IBM). Changes in weight were expressed as percentage differences between inclusion at the preoperative visit and the 1-year visit and categorized as 'weight loss' (> 5\% loss), 'stable weight' ( $\leq 5 \%$ change), or 'weight gain' ( $>5 \%$ gain). Similarly, changes between inclusion and the 2-year visit were calculated. The $5 \%$ cut-off was chosen according to standard recommendations to reduce the risk of weightrelated diseases and cancer [36, 37]. WHR was calculated as the ratio between the WC and the hip circumference. WHO recommends that a woman's WHR is $\leq 0.85$ [38]. Patients were stratified into four groups according to whether they remained or changed category $(\leq 0.85$ or $>0.85)$. Weight change and WHR categories were analyzed in relation to preoperative patient characteristics with non-parametric tests (Kruskal-Wallis) since several variables were not normally distributed. The median and interquartile ranges (IQR) are presented. Chi-square tests were used to analyze categorical variables in relation to weight change and WHR categories.

ABSI was calculated using the definition WC/ $\left(\mathrm{BMI}^{2 / 3} \times\right.$ height $\left.^{1 / 2}\right)$ with $\mathrm{WC}$ and height expressed in meters [30]. Patients' ABSI values were converted to $Z$-scores and divided into quintiles. The difference between ABSI at inclusion and ABSI at the 1-year visit was then calculated and converted into $Z$-scores. Patients with an ABSI difference $Z$-score in the 2 nd to 4 th quintile were considered stable, while patients with a difference in the 1st quintile were considered as having downward change in ABSI, and patients with a difference in the 5th quintile of upward change.

Breast cancer events included ipsilateral, contralateral, and regional recurrences, as well as distant metastasis. Breast cancer-free interval was censored at the time of a non-breast cancer-related death or at the time of the last follow-up prior to 1 July 2016 for patients who were alive and event-free prior to this date. Among the 1,317 patients, a total of 165 patients had any recurrence, of which 104 were distant metastasis, and 77 patients with a prior recurrence died. Of the 1,152 patients without recurrence, 59 died. In the subgroup of 1,178 patients analyzed for anthropometric changes, 138 recurrences occurred (87 distant), and 62 died. 
Fig. 1 Inclusion flowchart showing the number of included and excluded patients

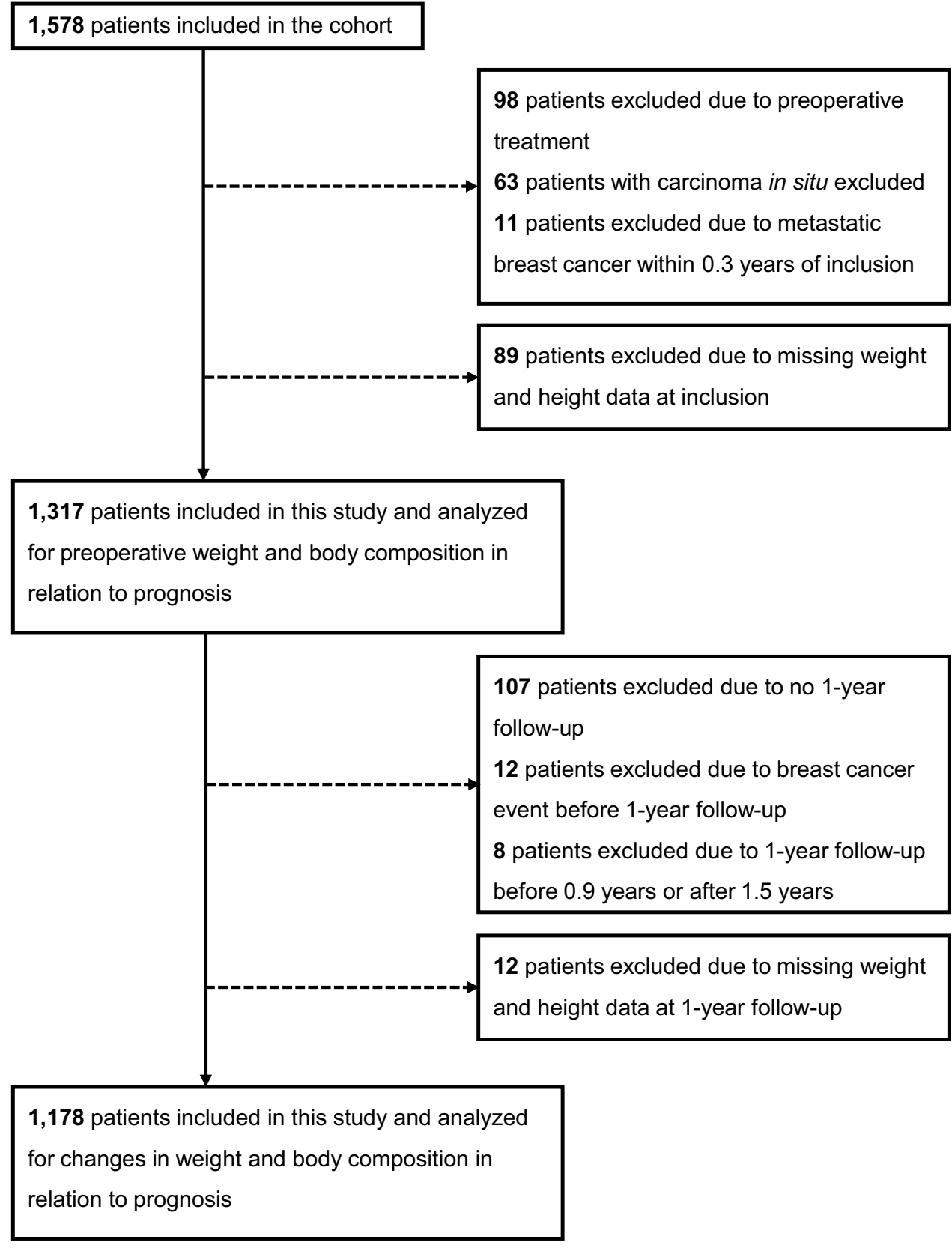

Of the 1,040 patients without breast cancer events, 47 died. Overall survival was calculated until death due to any cause.

For all variables indicating changes, including weight (gain or loss versus stable weight), WHR category changes (over the $>0.85$ cut-off versus remaining in the same category), or ABSI change (upwards or downwards versus 2-4 quintile), landmark analyses were performed where the event-free interval was calculated from the date of the 1-year follow-up visit. Univariable survival analyses (Kaplan-Meier) were performed. Cox regressions were used to calculate adjusted Hazard Ratios (HR) with $95 \%$ confidence intervals (CI) and adjusted $p$ values. All models were adjusted for invasive tumor size ( $>20 \mathrm{~mm}$ or skin/muscular involvement), any axillary nodal involvement, histological grade III, ER status, age at diagnosis (continuous), and the natural logarithm (ln) of preoperative weight. Adjustment for the preoperative ABSI Z-score was included in models investigating impact of ABSI changes. Further adjustments were made for any alcohol consumption and smoking or treatments, including a history of chemotherapy, radiotherapy, tamoxifen, and AI prior to any event.

To examine whether there were effect modifications for preoperative $\mathrm{BMI} \geq 25 \mathrm{~kg} / \mathrm{m}^{2}$, age $\geq 50$ or $\geq 70$ years at inclusion, tumor characteristics (tumor size $>20 \mathrm{~mm}$ or skin/muscular involvement, any axillary nodal involvement, histological grade III, or ER status), and treatments (chemotherapy, 
radiotherapy, tamoxifen, or AI) on the associations between weight change categories and prognosis, multiplicative interaction variables between these factors and the categories 'weight loss' and 'weight gain' were calculated. To examine whether there were effect modifications of tumor characteristics or treatments, multiplicative interaction variables between these factors and the WHR categories were calculated. All $p$ values were two-sided, and each $p$ value should be interpreted as the level of evidence against each null hypothesis. Since this is an exploratory study, nominal $p$ values are presented without adjustments for multiple testing.

\section{Results}

\section{Patient characteristics}

Patient characteristics and clinical data are presented in Table 1. In the group of patients who lost weight, the median weight loss was $-7.8 \%$, while the median weight gain was $+7.7 \%$ in the group that gained weight. As there were only 35 patients (3.0\%) who lost $>10 \%$ and only 44 patients $(3.7 \%)$ who gained $>10 \%$ of their preoperative weight, no further subdivision of weight change categories was performed. The median age at inclusion was 61 years (range 24-87 years). Preoperatively, patients who lost weight were older, weighed more, had greater WHR at inclusion, while patients who gained weight were younger, weighed less, and had lower WHR (all $P_{\mathrm{s}} \leq 0.043$ ). History of chemotherapy was less common among patients who had a stable weight $(p<0.0001)$ and use of AI but no tamoxifen by the 1 -year visit was less common among patients who gained weight $(p=0.006)$. Follow-up with body measurements was available for 1,041 patients at the 2-year visit. The majority (76.8\%) remained in the same weight change category as for the 1-year visit. All further analyses are therefore based on the 1-year visit to optimize follow-up time.

\section{Tumor characteristics}

Tumor characteristics are presented in Table 2. The patients who lost weight had more axillary node involvement and a higher frequency of histological grade III tumors, thus more aggressive tumors. The patients who had stable weight had a higher proportion of $\mathrm{ER}+$ and $\mathrm{PR}+$ tumors (all $p_{\mathrm{s}} \leq 0.049$ ).

\section{Breast cancer-free interval}

Patients were followed for up to 13 years from inclusion. The 1,317 patients aged 24-99 years were included and analyzed for preoperative weight and body composition in relation to the risk of breast cancer events; the median follow-up time was 5.0 years (IQR 3.0-7.2) for the 1,093 patients still at risk. Of the 165 breast cancer events, 33 occurred in patients with ER- disease, 132 in patients with ER+, while ER status was missing for one patient. Overall, preoperative (ln) weight or a preoperative $\mathrm{BMI} \geq 25 \mathrm{~kg} / \mathrm{m}^{2}$ were associated with recurrence risk ( $p=0.024$ and $p=0.013)$. The level of evidence became somewhat weaker after adjustments for age and tumor characteristics and when only the 1,178 patients analyzed for changes in body measures were included.

Overall, there was no association between weight change categories and recurrence risk (LogRank $p=0.35$ ). To elucidate whether any association between weight change and risk for events was present in subgroups of patients, exploratory analyses of effect modification according to preoperative BMI, age, tumor characteristics, and treatments were performed.

\section{Age and weight change in relation to prognosis}

Effect modifications between age and weight changes were detected. Patients were stratified into three age groups ( $<50$ years $/ 50$ to $<70$ years $/ \geq 70$ years; Fig. 2 ). Age $<50$ years was used as a proxy for premenopausal status. An interaction was found between age $\geq 50$ years and weight gain (adjusted $P_{\text {interaction }}=0.033$ ), but not with weight loss, on recurrence risk. The patients were stratified by age $\geq 50$ years. Patients $<50$ years who gained weight had a twofold recurrence risk compared to other patients, $\mathrm{HR}_{\text {adj }}$ 2.64 (95\% CI 1.28-5.45), while weight loss was not associated with recurrences $\left(P_{\text {adj }}=0.72\right)$. In patients $\geq 50$ years, no association was found between recurrences and weight change (both $P_{\text {adj }} \geq 0.84$ ).

When applying a different age cut-off ( $\geq 70$ years) to test whether there were effect modifications of old age on recurrence risk, an interaction was found between weight loss (adjusted $P_{\text {interaction }}=0.021$ ), but not with weight gain. Patients $\geq 70$ years who lost weight had a threefold recurrence risk, $\mathrm{HR}_{\mathrm{adj}} 3.47$ (95\% CI 1.06-11.33), while weight gain was not associated with recurrences. In women $<70$ years, no association was found between weight change and recurrences $\left(P_{\text {adj }} \geq 0.22\right)$.

No effect modifications of age were found for weight gain or loss with respect to death with either of the cut-offs ( $\geq 50$ or $\geq 70$ years). However, the oldest patients ( $\geq 70$ years) that lost weight also had an increased risk of death, $\mathrm{HR}_{\mathrm{adj}} 3.56$ (95\% CI 1.50-8.44). Eight patients in different age groups died within one year of the 1-year visit. When these patients were excluded, there was no association between weight loss and recurrence risk or death in the oldest age group. Weight change did not impact either recurrence risk or death in patients $50-<70$ years. 


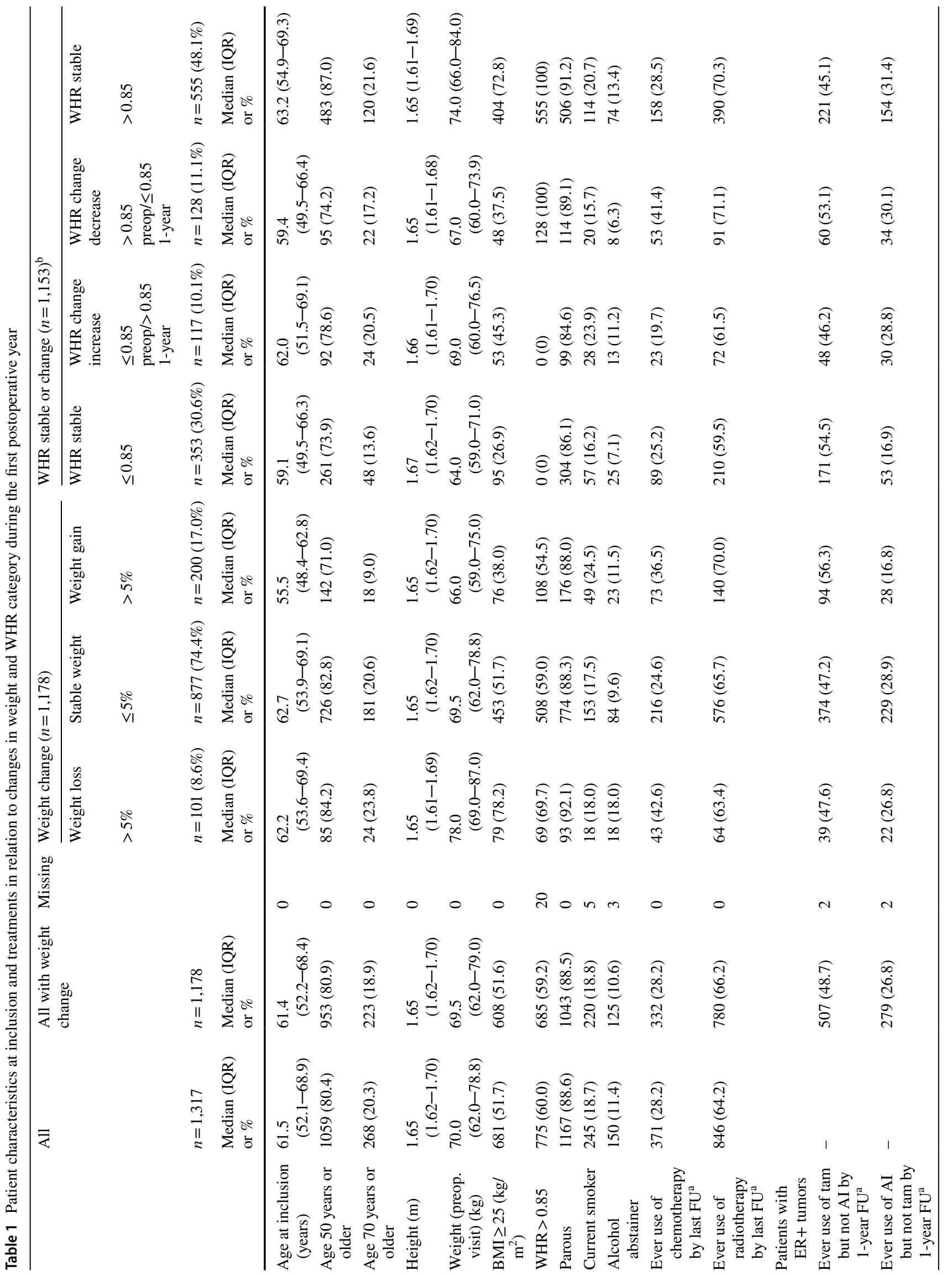




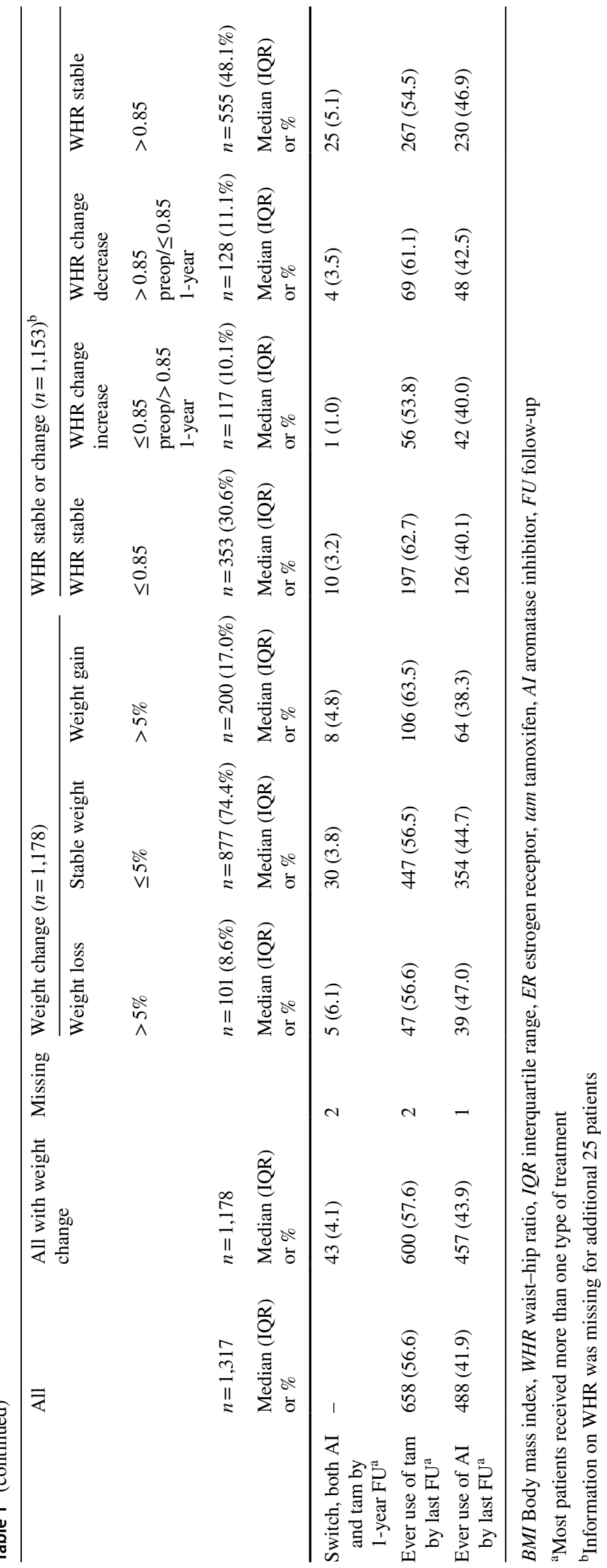


Table 2 Tumor characteristics at inclusion in relation to change in weight and WHR category during the first postoperative year

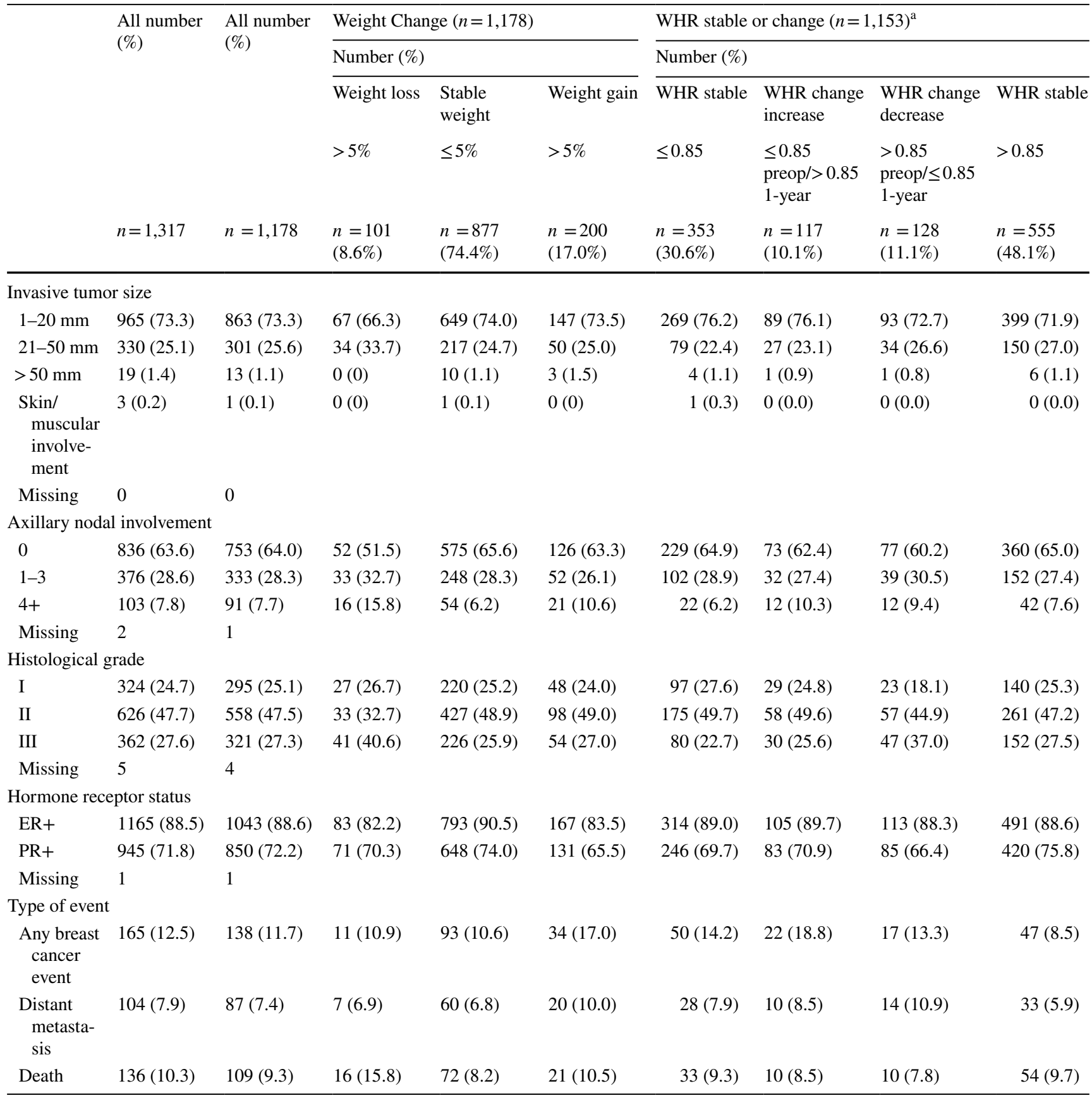

$E R$ Estrogen receptor, $P R$ progesterone receptor

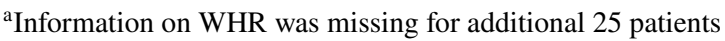

Preoperative BMI, tumor characteristics, treatments, and weight changes in relation to prognosis

There was no effect modification of preoperative BMI on the association between the weight change categories 'weight gain' and 'weight loss' and risk of recurrence or death (all adjusted $P_{\text {interactions }} \geq 0.39$ ). Furthermore, there were no effect modifications between tumor characteristics or treatments on the associations between weight gain or loss and recurrences or death (all adjusted $P_{\text {interactions }} \geq 0.096$ ).

\section{Preoperative WHR and changes during the first postoperative year in relation to prognosis}

For the 1,291 patients with complete preoperative body measurements, recurrence risk was not associated with 
A

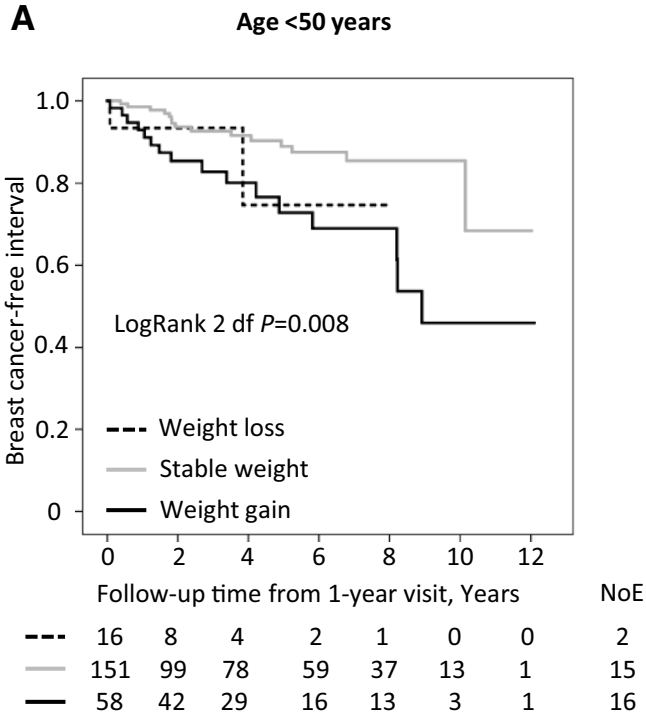

B Age 50 to $<70$ years

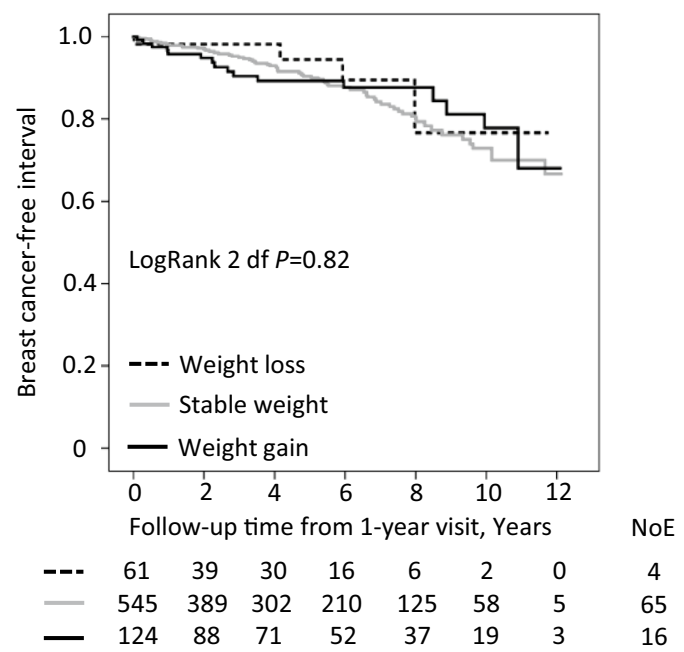

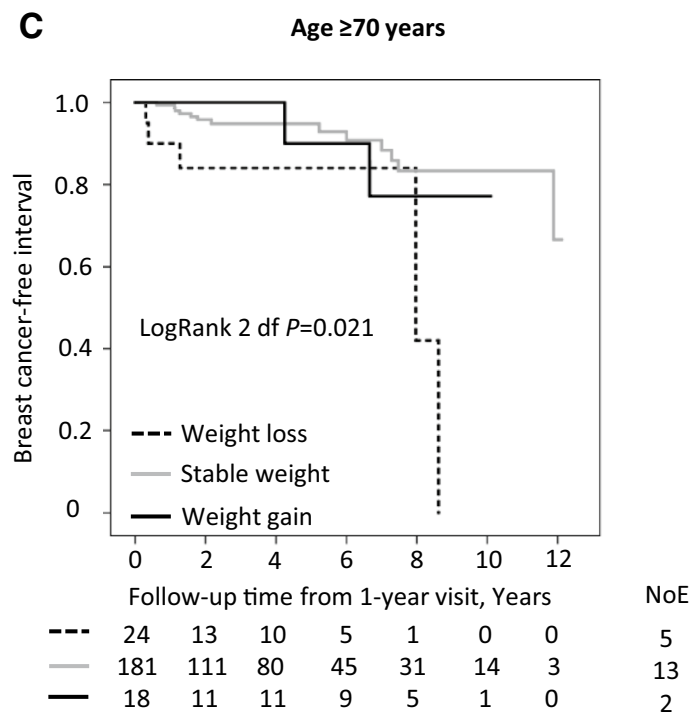

Fig. 2 Weight changes (> 5\%) compared to stable weight $(\max \pm 5 \%$ weight change) in relation to breast cancer-free interval in different age groups. a Patients $<50$ years. b Patients 50 to $<70$ years. c Patients $\geq 70$ years. Weight gain was associated with recurrence risk in patients $<50$ years, while weight loss was associated with recur-

preoperative WHR $>0.85$. In contrast, preoperative WHR $>0.85$ conferred higher risk of death (LogRank $\left.p=0.001 ; \mathrm{HR}_{\text {adj }} 1.44(95 \% \mathrm{CI} 0.99-2.10)\right)$. The results were slightly weaker when restricted to the 1,153 patients analyzed for changes in WHR category.

Patients were stratified into four groups based on changes between the preoperative and 1-year postoperative WHR (Group 1 stable $\leq 0.85$ at both visits; Group 2 WHR increased $\leq 0.85$ at preoperative and $>0.85$ at 1 -year visit; Group 3 WHR decreased $>0.85$ at preoperative and $\leq 0.85$ at 1 -year visit; and Group 4 stable $>0.85$ at both visits). rence risk in the oldest patients ( $\geq 70$ years). Weight change did not impact recurrence risk in patients 50 to $<70$ years old. The number of patients at each follow-up and number of events are displayed below the graphs. Since this is an ongoing study, there are fewer patients the longer the follow-up time

Overall, there was a tendency towards lower recurrence risk in the two stable WHR groups compared to the two groups that changed the WHR category (Fig. 3a). The association was somewhat weaker if 'weight gain' and 'weight loss' were also adjusted for.

Since both the curves for patients who remained in the same WHR category between preoperative and 1-year visit $(\leq 0.85$ or $>0.85)$ and both the curves for patients who changed category (increased or decreased) crossed over, these groups were combined into two groups of patients who either remained in the same or changed WHR category 
(Fig. 3b). When comparing stable versus changed WHR category groups, a substantially lower recurrence risk in the group of patients who remained in the same category was found compared to those who changed category, $\mathrm{HR}_{\text {adj }} 0.62$ (95\% CI 0.43-0.90). Results were essentially the same if 'weight gain' and 'weight loss' were also adjusted for.

Regarding overall survival, when comparing the four groups of patients who either remained in the same or changed WHR category, a WHR $>0.85$ at both visits conferred the highest risk of death ( $\operatorname{LogRank} p=0.014 ; \mathrm{HR}_{\text {adj }}$ 1.60 (95\% CI $0.98-2.59)$ ) when the group with $\leq 0.85$ at both visits was used as a reference. When comparing the two groups of patients who remained in the same WHR category with those who changed category, no difference was found. The results were essentially the same after further adjustment for 'weight gain' and 'weight loss.'

\section{ER status and WHR category changes versus stable WHR in relation to prognosis}

A strong effect modification was found between ER status and changes in WHR category on the recurrence risk (adjusted $P_{\text {interaction }}=0.007$ ). Patients with ER+ tumors who remained in the same WHR category had a lower recurrence risk than those who changed category, $\mathrm{HR}_{\text {adj }} 0.44$ (95\% CI 0.30-0.66). In contrast, patients with ER- tumors that remained in the same WHR category had a higher recurrence risk than those who changed category, $\mathrm{HR}_{\mathrm{adj}}$ 7.30 (95\% CI 0.98-54.08; Fig. 3c-f). No interaction was found between ER status and changes in WHR on overall survival $\left(P_{\text {interaction }}=0.22\right)$. Further adjustments for smoking and alcohol abstinence or treatments revealed essentially the same results.

\section{Tumor characteristics, treatment, and WHR category changes versus stable WHR in relation to prognosis}

Except for ER status, no effect modifications were found between tumor characteristics and WHR category change on recurrence risk or death (all $P_{\text {interactions }} \geq 0.086$ ). Similarly, there were no effect modifications between radiotherapy or chemotherapy and WHR category change on recurrence risk or death. Among patients with ER+tumors, no effect modification was found between ever use of AIs and WHR category change (all adjusted $P_{\text {interactions }} \geq 0.23$ ). There was weak evidence of an effect modification between ever use of tamoxifen and WHR category change on the recurrence risk (adjusted $P_{\text {interaction }}=0.052$ ) but not death (adjusted $P_{\text {interaction }}=0.32$ ).

\section{Preoperative $\mathrm{ABSI}$ and postoperative changes in relation to prognosis}

ABSI was calculated for 1,291 patients with complete preoperative body measurements. Overall survival was strongly associated with preoperative ABSI ( $\mathrm{HR}_{\text {adj }} 1.26(95 \% \mathrm{CI}$ 1.10-1.43) per quintile. Preoperative ABSI was not associated with recurrence risk $\left(\operatorname{LogRank} P_{\text {trend }}=0.84\right)$. The results were essentially the same for the 1,153 patients analyzed for changes in ABSI.

Changes in ABSI, either downwards $(n=230)$ or upwards $(n=230)$, were not associated with recurrence risk or death when compared to patients with stable ABSI $(n=693)$. No further analysis of ABSI was conducted.

\section{Discussion}

In this study, 1-year postoperative changes in weight and WHR in breast cancer patients impacted differently on prognosis depending on age and tumor ER status. However, the association between changes in anthropometric measures and clinical outcome was not dependent on overweight. In younger patients, weight gain was associated with higher recurrence risk. Changes between WHR categories were associated with higher recurrence risk in patients with $\mathrm{ER}+$ tumors and lower recurrence risk in patients with ER- tumors. High preoperative ABSI was strongly associated with shorter overall survival but not with recurrence risk.

In the present study, patients $<50$ years were most likely to gain weight, which was associated with a higher recurrence risk. This is consistent with a recent scoping review, which concluded that younger chemotherapy-treated premenopausal patients were particularly at risk for weight gain [22]. One previous study showed a higher recurrence risk in premenopausal patients [10]. Another study compared the impact of BMI changes in clinical trials and found increases in BMI by 1 year to negatively impact outcomes only in pre-/ peri-/early post-menopausal trial patients [19]. However, we found no benefit of weight loss in this age group and retaining preoperative weight might be most beneficial.

The oldest patients ( $\geq 70$ years) that lost weight had a poorer prognosis compared to other old patients. However, this was no longer evident after exclusion of patients that had died within one year after the 1-year postoperative visit, which suggests reverse causality and a symptom of an underlying disease where frailty and muscle wasting might be present. Multiple observational studies have reported poor breast cancer prognosis associated with weight loss $[6,7,9$, $11,12,15,16,18]$. However, a systematic review indicated a considerable risk of bias in some studies because of lack 
A

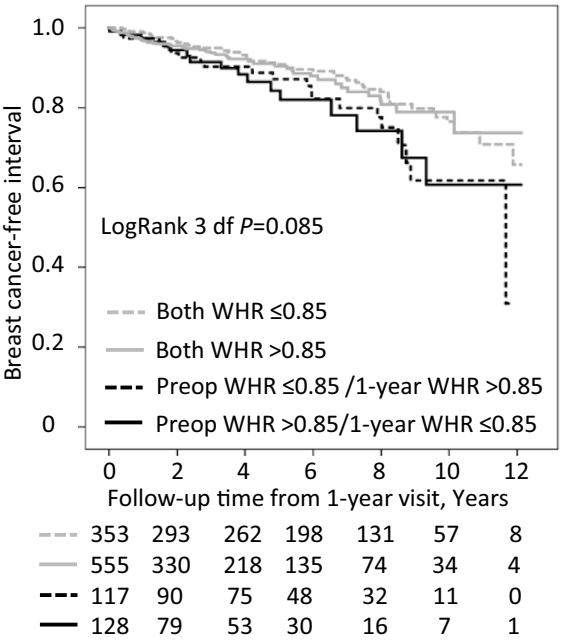

\section{Patients with ER negative tumors}

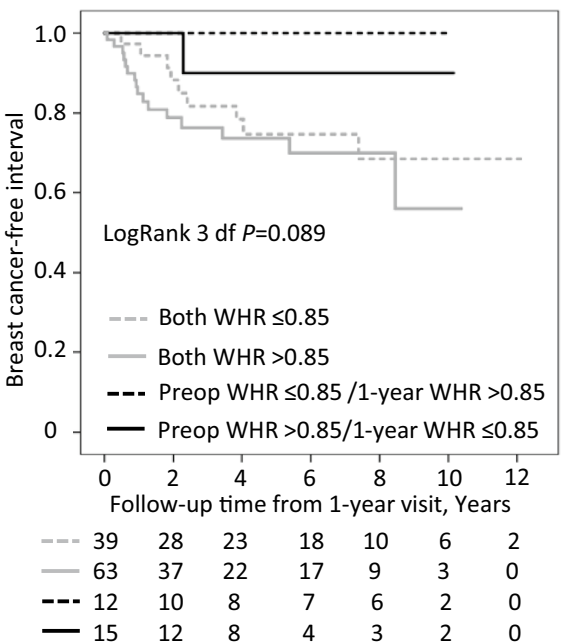

E Patients with ER positive tumors

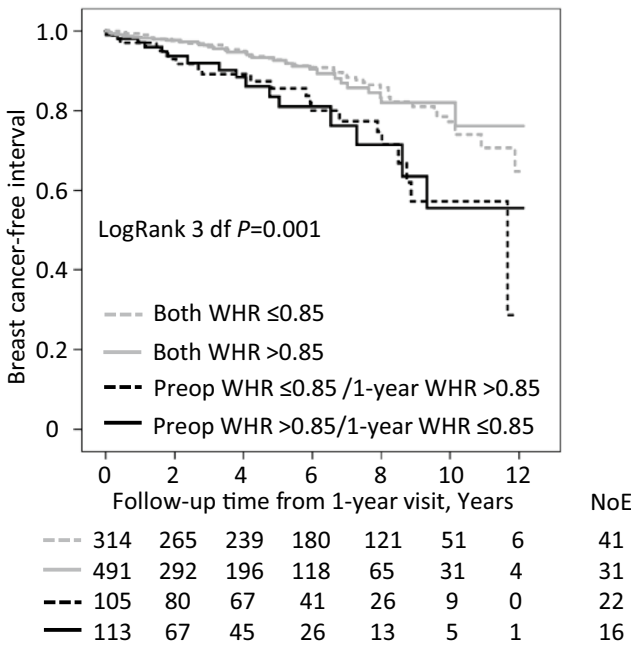

\section{B \\ All patients}

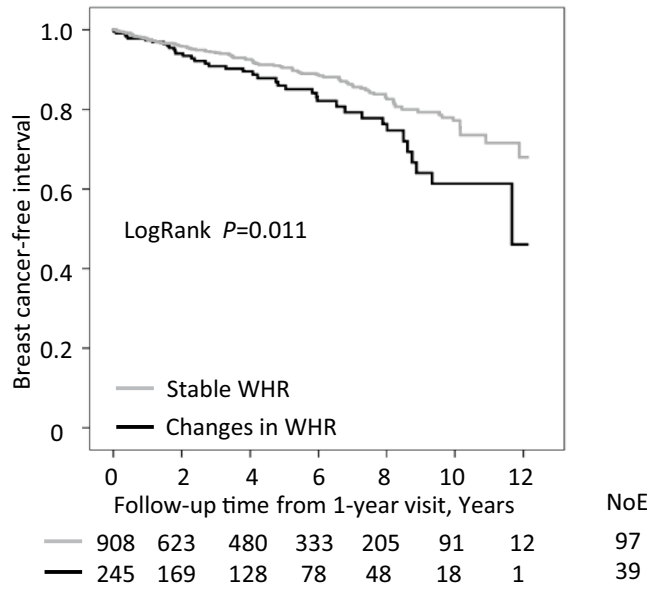

D Patients with ER negative tumors

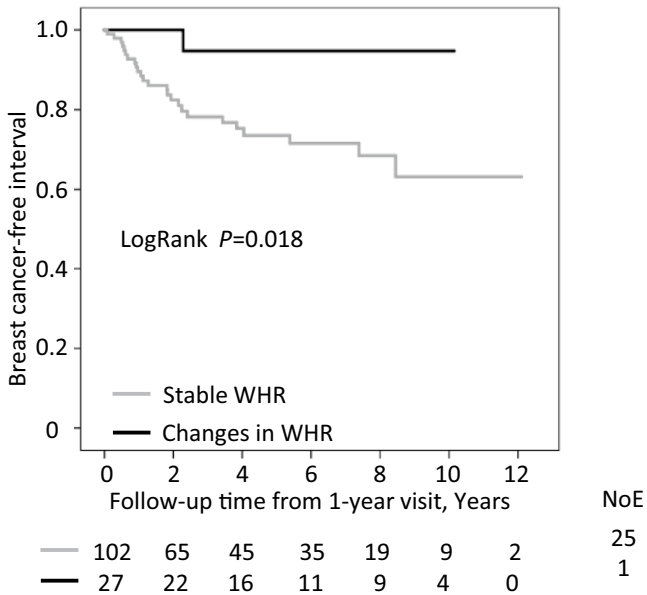

F Patients with ER positive tumors

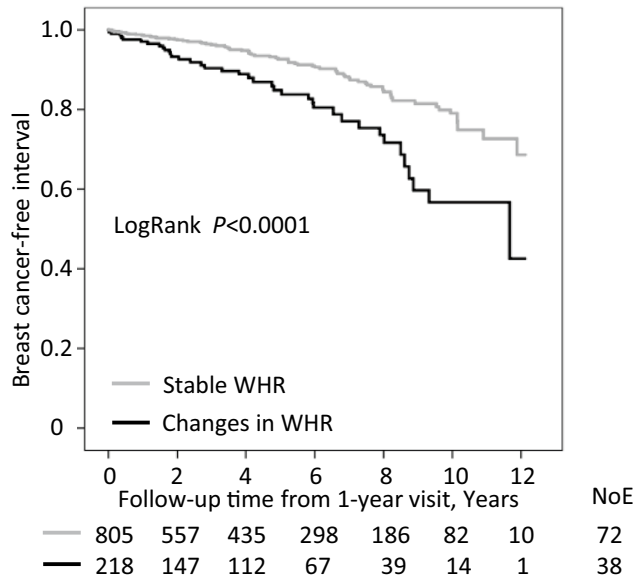


4Fig. 3 Changes in WHR, increasing (preoperative WHR $\leq 0.85$ $/ 1$-year WHR $>0.85$ ) and decreasing (preoperative WHR $>0.85 / 1$ year WHR $\leq 0.85$ ), compared to stable WHR (both WHR $\leq 0.85$ and both WHR $<0.85$ ) in relation to breast cancer-free interval according to tumor ER status. a Increasing WHR and decreasing WHR versus stable WHR $\leq 0.85$ and stable WHR $>0.85$ in all patients. b Changes in WHR category versus stable WHR in all patients. c Increasing WHR and decreasing WHR versus stable WHR $\leq 0.85$ and stable WHR $>0.85$ in patients with ER- tumors. d Changes in WHR category versus stable WHR in patients with ER- tumors. e Increasing WHR and decreasing WHR versus stable WHR $\leq 0.85$ and stable WHR $>0.85$ in patients with ER+ tumors. f Changes in WHR category versus stable WHR in patients with ER+ tumors. The number of patients at each follow-up and number of events are displayed below the graphs. Since this is an ongoing study, there are fewer patients the longer the follow-up time

of information on whether the weight loss was intentional or not [39]. No association was found between weight changes and recurrences or death in the age group 50 to $<70$ years, which might reflect the mix of peri- and early post-menopausal patients. Further, changes in weight and BMI do not necessarily reflect body fat distribution, which can be better measured by other methods.

Individuals with a normal weight and BMI might still have an unhealthy metabolic body composition with excess body fat, especially central accumulation, referred to as sarcopenic obesity [40]. In the present study, measurements of WHR and the new index ABSI were used to capture central body fat accumulation. Patients with preoperative WHR $>0.85$ had a poorer overall survival, which is in line with most [27, 41-43], but not all [12, 44] studies. The change in WHR category conferred prognostic impact with strong effect modification with ER status independent of weight change in the present study. To the authors' knowledge, this is the first study to investigate the prognostic impact of early changes in anthropometric measures in breast cancer patients, and it is unknown whether this difference reflects a change in hormonal profile in endocrinetreated patients or impacts therapy response to one or more treatment types. The median follow-up was only five years from inclusion. Most recurrences occur within five years in patients with ER- tumors, while ER+ tumors tend to recur over a longer period of time.

Different treatments could affect both body composition and prognosis [45]. Smoking also impacts body composition in young women [46], as well as the clinical outcome after endocrine therapy [47]. Smoking and alcohol consumption or treatments were included in separate adjustment models but did not explain the results. Menopause occurred in some patients either as result of age or treatment, which might have affected body constitution [48].

We hypothesize that the different prognostic impacts of weight and WHR changes according to age and tumor ER status in part reflect shifts in the inflammatory and hormonal profile caused by changes in the central adipose tissue. The release of free fatty acids, particularly associated with abdominal visceral adipocytes [29], activates the

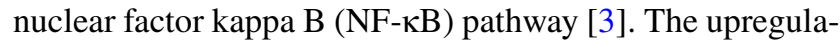
tion of inflammatory cytokines and subsequent increases in aromatase activity and estrogen synthesis might stimulate $\mathrm{ER}+$ breast cancer cells [3]. The generation of crown-like structures associated with inflammation and increased aromatase activity might also play a role [49]. Increased levels of insulin and insulin-like growth factors (IGFs), particularly associated with central obesity [50], also increase the bioavailability of estrogens by downregulation of sex hormonebinding globulin (SHBG) [51]. Surprisingly, weight loss has been associated with increase in IGF-1 levels in postmenopausal women in contrast to findings in animal studies [52], reflecting the complexity of the pathways involved in changes in body measures. However, factors that promote tumor growth may not affect prognosis in patients who died from other causes and it was also observed that changes in anthropometric measures impacted recurrence risk and death somewhat differently.

Our study confirmed previous findings that higher preoperative ABSI was strongly associated with overall survival but no association with breast cancer recurrences was found. The association with overall survival was evident in patients with and without a recurrence but was stronger in patients without a previous recurrence (data not shown). A previous study reported that higher ABSI increased cancer mortality in women [32]. Raising ABSI over a 7-year period was associated with greater mortality [31]. In the present study, however, 1-year changes in ABSI were not associated with recurrence risk or death.

A significant strength of the present study is that research nurses obtained body measurements at both visits to avoid the risk of recall bias or self-presentational bias. The cohort is population-based and representative for breast cancer patients treated at this clinic [47] with excellent followup rates [53]. The patients were included preoperatively before any procedures that could affect body composition had taken place. Patients of all ages were included, which allowed for the study of the prognostic impacts of anthropometric changes in different age groups. However, there are limitations. Importantly, no information was available as to whether weight change was intentional or how fast the weight changes occurred. Since unintentional weight loss can arise due to an underlying disease, this can lead to reverse causality. Rapid weight loss might have other biologic effects than more gradual loss [54]. No information on muscle or fat mass was available for evaluation of sarcopenic obesity. Additionally, information on exercise, comorbidities, and socioeconomic status were missing, all of which might impact prognosis [55-57]. Only weight change by the 1 -year visit was analyzed, although $76.8 \%$ remained in the 
same weight change category by the 2 -year visit. Chemotherapy, which is administered during the first postoperative year, conferred both weight gain and loss, while late treatment effects were not captured. Few events occurred in some subgroups, resulting in lower power. Multivariable analyses were performed, including several potential confounders. Since this is an observational study, residual confounding remains possible.

In conclusion, changes in weight and anthropometric measures during the first postoperative year impacted differently on breast cancer prognosis depending on age and tumor ER status, but were independent of overweight. Whether the effect modifications of ER status results from endocrine therapy or impacts therapy response remains to be elucidated and confirmed in an independent cohort, preferably a randomized trial. Stratification of patients according to age and tumor ER status in future studies could further elucidate the impact of weight changes in subgroups of patients. Weight gain was associated with recurrences only in patients $<50$ years. Weight loss did not improve prognosis in any age group. This challenges the prevailing opinion that weight loss must be beneficial in overweight patients and further research is imperative before recommending weight loss for all overweight breast cancer patients.

Acknowledgments Open access funding provided by Lund University. We thank our research nurses Linda Agren, Helén Thell, Jessica Åkesson, Anette Ahlin Gullers, Monika Eberhard Mészaros, Maj-Britt Hedenblad, Karin Henriksson, and Anette Möller. We also thank Erika Bågeman, Maria Henningson, and Maria Hjertberg for data entry. This work was supported by Grants from The Swedish Cancer Society (CAN2017/368), the Medical Faculty at Lund University, the Mrs. Berta Kamprad Foundation, the South Swedish Health Care Region (Region Skåne ALF 40620), the Swedish Breast Cancer Group (BRO), and the Lund Hospital Fund. The funding agencies played no role in the design of the study, the collection, analysis, and interpretation of the data, the writing of the manuscript, or in the decision to submit the manuscript for publication.

\section{Compliance with ethical standards}

Conflict of interest The authors declare that they have no conflict of interest.

Open Access This article is distributed under the terms of the Creative Commons Attribution 4.0 International License (http://creativeco mmons.org/licenses/by/4.0/), which permits unrestricted use, distribution, and reproduction in any medium, provided you give appropriate credit to the original author(s) and the source, provide a link to the Creative Commons license, and indicate if changes were made.

\section{References}

1. Carioli G, Malvezzi M, Rodriguez T, Bertuccio P, Negri E, La Vecchia C (2017) Trends and predictions to 2020 in breast cancer mortality in Europe. Breast 36:89-95. https://doi.org/10.1016/j. breast.2017.06.003

2. DeSantis CE, Ma J, Goding Sauer A, Newman LA, Jemal A (2017) Breast cancer statistics, 2017, racial disparity in mortality by state. CA Cancer J Clin 67(6):439-448. https://doi. org/10.3322/caac. 21412

3. Picon-Ruiz M, Morata-Tarifa C, Valle-Goffin JJ, Friedman ER, Slingerland JM (2017) Obesity and adverse breast cancer risk and outcome: Mechanistic insights and strategies for intervention. CA Cancer J Clin 67(5):378-397. https://doi.org/10.3322/caac.21405

4. Chan DS, Vieira AR, Aune D, Bandera EV, Greenwood DC, McTiernan A, Navarro Rosenblatt D, Thune I, Vieira R, Norat T (2014) Body mass index and survival in women with breast cancer-systematic literature review and meta-analysis of 82 follow-up studies. Ann Oncol 25(10):1901-1914. https://doi.org/10.1093/ annonc/mdu042

5. Wisse A, Tryggvadottir H, Simonsson M, Isaksson K, Rose C, Ingvar C, Jernström H (2018) Increasing preoperative body size in breast cancer patients between 2002 and 2016: implications for prognosis. Cancer Causes Control 29(7):643-656. https://doi. org/10.1007/s10552-018-1042-z

6. Caan BJ, Kwan ML, Hartzell G, Castillo A, Slattery ML, Sternfeld B, Weltzien E (2008) Pre-diagnosis body mass index, postdiagnosis weight change, and prognosis among women with early stage breast cancer. Cancer Causes Control 19(10):1319-1328. https://doi.org/10.1007/s10552-008-9203-0

7. Bradshaw PT, Ibrahim JG, Stevens J, Cleveland R, Abrahamson PE, Satia JA, Teitelbaum SL, Neugut AI, Gammon MD (2012) Postdiagnosis change in bodyweight and survival after breast cancer diagnosis. Epidemiology 23(2):320-327. https://doi. org/10.1097/EDE.0b013e31824596a1

8. Caan BJ, Emond JA, Natarajan L, Castillo A, Gunderson EP, Habel L, Jones L, Newman VA, Rock CL, Slattery ML, Stefanick ML, Sternfeld B, Thomson CA, Pierce JP (2006) Post-diagnosis weight gain and breast cancer recurrence in women with early stage breast cancer. Breast Cancer Res Treat 99(1):47-57. https ://doi.org/10.1007/s10549-006-9179-y

9. Caan BJ, Kwan ML, Shu XO, Pierce JP, Patterson RE, Nechuta SJ, Poole EM, Kroenke CH, Weltzien EK, Flatt SW, Quesenberry CP, Jr, Holmes MD, Chen WY (2012) Weight change and survival after breast cancer in the after breast cancer pooling project. Cancer Epidemiol Biomark Prev 21(8):1260-1271. https://doi. org/10.1158/1055-9965.EPI-12-0306

10. Camoriano JK, Loprinzi CL, Ingle JN, Therneau TM, Krook JE, Veeder MH (1990) Weight change in women treated with adjuvant therapy or observed following mastectomy for nodepositive breast cancer. J Clin Oncol 8(8):1327-1334. https://doi. org/10.1200/JCO.1990.8.8.1327

11. Cespedes Feliciano EM, Kroenke CH, Bradshaw PT, Chen WY, Prado CM, Weltzien EK, Castillo AL, Caan BJ (2017) Postdiagnosis weight change and survival following a diagnosis of early-stage breast cancer. Cancer Epidemiol Biomark Prev 26(1):44-50. https://doi.org/10.1158/1055-9965.EPI-16-0150

12. Chen X, Lu W, Zheng W, Gu K, Chen Z, Zheng Y, Shu XO (2010) Obesity and weight change in relation to breast cancer survival. Breast Cancer Res Treat 122(3):823-833. https://doi. org/10.1007/s10549-009-0708-3

13. Jeon YW, Lim ST, Choi HJ, Suh YJ (2014) Weight change and its impact on prognosis after adjuvant TAC (docetaxel-doxorubicin-cyclophosphamide) chemotherapy in Korean women with node-positive breast cancer. Med Oncol 31(3):849. https://doi. org/10.1007/s12032-014-0849-Z

14. Levine EG, Raczynski JM, Carpenter JT (1991) Weight gain with breast cancer adjuvant treatment. Cancer 67(7):1954-1959

15. Mutschler NS, Scholz C, Friedl TWP, Zwingers T, Fasching PA, Beckmann MW, Fehm T, Mohrmann S, Salmen J, Ziegler C, 
Jager B, Widschwendter P, de Gregorio N, Schochter F, Mahner S, Harbeck N, Weissenbacher T, Juckstock J, Janni W, Rack B (2018) Prognostic impact of weight change during adjuvant chemotherapy in patients with high-risk early breast cancer: results from the ADEBAR study. Clin Breast Cancer 18(2):175183. https://doi.org/10.1016/j.clbc.2018.01.008

16. Nichols HB, Trentham-Dietz A, Egan KM, Titus-Ernstoff L, Holmes MD, Bersch AJ, Holick CN, Hampton JM, Stampfer MJ, Willett WC, Newcomb PA (2009) Body mass index before and after breast cancer diagnosis: associations with all-cause, breast cancer, and cardiovascular disease mortality. Cancer Epidemiol Biomark Prev 18(5):1403-1409. https://doi. org/10.1158/1055-9965.EPI-08-1094

17. Raghavendra A, Sinha AK, Valle-Goffin J, Shen Y, Tripathy D, Barcenas CH (2018) Determinants of weight gain during adjuvant endocrine therapy and association of such weight gain with recurrence in long-term breast cancer survivors. Clin Breast Cancer 18(1):e7-e13. https://doi.org/10.1016/j. clbc.2017.11.006

18. Thivat E, Therondel S, Lapirot O, Abrial C, Gimbergues P, Gadea E, Planchat E, Kwiatkowski F, Mouret-Reynier MA, Chollet P, Durando X (2010) Weight change during chemotherapy changes the prognosis in non metastatic breast cancer for the worse. BMC Cancer 10:648. https://doi.org/10.1186/1471-2407-10-648

19. Yerushalmi R, Dong B, Chapman JW, Goss PE, Pollak MN, Burnell MJ, Levine MN, Bramwell VHC, Pritchard KI, Whelan TJ, Ingle JN, Shepherd LE, Parulekar WR, Han L, Ding K, Gelmon KA (2017) Impact of baseline BMI and weight change in CCTG adjuvant breast cancer trials. Ann Oncol 28(7):1560-1568. https ://doi.org/10.1093/annonc/mdx152

20. Demark-Wahnefried W, Campbell KL, Hayes SC (2012) Weight management and its role in breast cancer rehabilitation. Cancer 118(8 Suppl):2277-2287. https://doi.org/10.1002/cncr.27466

21. Sestak I, Harvie M, Howell A, Forbes JF, Dowsett M, Cuzick J (2012) Weight change associated with anastrozole and tamoxifen treatment in postmenopausal women with or at high risk of developing breast cancer. Breast Cancer Res Treat 134(2):727-734. https://doi.org/10.1007/s10549-012-2085-6

22. Pedersen B, Delmar C, Lorincz T, Falkmer U, Gronkjaer M (2018) Investigating changes in weight and body composition among women in adjuvant treatment for breast cancer: a scoping review. Cancer Nurs 42:91-105. https://doi.org/10.1097/NCC.00000 00000000590

23. Shen W, Punyanitya M, Chen J, Gallagher D, Albu J, Pi-Sunyer X, Lewis CE, Grunfeld C, Heshka S, Heymsfield SB (2006) Waist circumference correlates with metabolic syndrome indicators better than percentage fat. Obesity (Silver Spring) 14(4):727-736. https://doi.org/10.1038/oby.2006.83

24. Maturana MA, Spritzer PM (2002) Association between hyperinsulinemia and endogenous androgen levels in peri- and postmenopausal women. Metabolism 51(2):238-243

25. Cerhan JR, Moore SC, Jacobs EJ, Kitahara CM, Rosenberg PS, Adami HO, Ebbert JO, English DR, Gapstur SM, Giles GG, Horn-Ross PL, Park Y, Patel AV, Robien K, Weiderpass E, Willett WC, Wolk A, Zeleniuch-Jacquotte A, Hartge P, Bernstein L, Berrington de Gonzalez A (2014) A pooled analysis of waist circumference and mortality in 650,000 adults. Mayo Clin Proc 89(3):335-345. https://doi.org/10.1016/j.mayocp.2013.11.011

26. Bandera EV, Fay SH, Giovannucci E, Leitzmann MF, Marklew R, McTiernan A, Mullee A, Romieu I, Thune I, Uauy R, Wiseman MJ, World Cancer Research Fund International Continuous Update Project Panel (2016) The use and interpretation of anthropometric measures in cancer epidemiology: a perspective from the world cancer research fund international continuous update project. Int J Cancer 139(11):2391-2397. https://doi.org/10.1002/ ijc. 30248
27. George SM, Bernstein L, Smith AW, Neuhouser ML, Baumgartner KB, Baumgartner RN, Ballard-Barbash R (2014) Central adiposity after breast cancer diagnosis is related to mortality in the health, eating, activity, and lifestyle study. Breast Cancer Res Treat 146(3):647-655. https://doi.org/10.1007/s10549-014-3048-x

28. Kwan ML, John EM, Caan BJ, Lee VS, Bernstein L, Cheng I, Gomez SL, Henderson BE, Keegan TH, Kurian AW, Lu Y, Monroe KR, Roh JM, Shariff-Marco S, Sposto R, Vigen C, Wu AH (2014) Obesity and mortality after breast cancer by race/ethnicity: the California Breast Cancer Survivorship Consortium. Am J Epidemiol 179(1):95-111. https://doi.org/10.1093/aje/kwt233

29. Snijder MB, van Dam RM, Visser M, Seidell JC (2006) What aspects of body fat are particularly hazardous and how do we measure them? Int J Epidemiol 35(1):83-92. https://doi. org/10.1093/ije/dyi253

30. Krakauer NY, Krakauer JC (2012) A new body shape index predicts mortality hazard independently of body mass index. PLoS ONE 7(7):e39504. https://doi.org/10.1371/journal.pone.0039504

31. Krakauer NY, Krakauer JC (2014) Dynamic association of mortality hazard with body shape. PLoS ONE 9(2):e88793. https://doi. org/10.1371/journal.pone.0088793

32. Dhana K, Kavousi M, Ikram MA, Tiemeier HW, Hofman A, Franco OH (2016) Body shape index in comparison with other anthropometric measures in prediction of total and cause-specific mortality. J Epidemiol Commun Health 70(1):90-96. https://doi. org/10.1136/jech-2014-205257

33. Thomson CA, Garcia DO, Wertheim BC, Hingle MD, Bea JW, Zaslavsky O, Caire-Juvera G, Rohan T, Vitolins MZ, Thompson PA, Lewis CE (2016) Body shape, adiposity index, and mortality in postmenopausal women: findings from the Women's Health Initiative. Obesity (Silver Spring) 24(5):1061-1069. https://doi. org/10.1002/oby.21461

34. Simonsson M, Markkula A, Bendahl PO, Rose C, Ingvar C, Jernström H (2014) Pre- and postoperative alcohol consumption in breast cancer patients: impact on early events. SpringerPlus 3:261. https://doi.org/10.1186/2193-1801-3-261

35. Jernström H, Bågeman E, Rose C, Jönsson PE, Ingvar C (2009) CYP2C8 and CYP2C9 polymorphisms in relation to tumour characteristics and early breast cancer related events among 652 breast cancer patients. Br J Cancer 101(11):1817-1823. https:// doi.org/10.1038/sj.bjc. 6605428

36. Doyle C, Kushi LH, Byers T, Courneya KS, Demark-Wahnefried W, Grant B, McTiernan A, Rock CL, Thompson C, Gansler T, Andrews KS, Nutrition PA, Cancer Survivorship Advisory C, American Cancer S (2006) Nutrition and physical activity during and after cancer treatment: an American Cancer Society guide for informed choices. CA Cancer J Clin 56(6):323-353

37. Bantle JP, Wylie-Rosett J, Albright AL, Apovian CM, Clark NG, Franz MJ, Hoogwerf BJ, Lichtenstein AH, Mayer-Davis E, Mooradian AD, Wheeler ML (2006) Nutrition recommendations and interventions for diabetes-2006: a position statement of the American Diabetes Association. Diabetes Care 29(9):2140-2157. https://doi.org/10.2337/dc06-9914

38. World Health Organization (2008) Waist circumference and waisthip ratio: report of a WHO expert consultation. https://apps.who. int/iris/bitstream/handle/10665/44583/9789241501491_eng. pdf?ua $=1$

39. Jackson SE, Heinrich M, Beeken RJ, Wardle J (2017) Weight loss and mortality in overweight and obese cancer survivors: a systematic review. PLoS ONE 12(1):e0169173. https://doi.org/10.1371/ journal.pone.0169173

40. Muller MJ, Lagerpusch M, Enderle J, Schautz B, Heller M, BosyWestphal A (2012) Beyond the body mass index: tracking body composition in the pathogenesis of obesity and the metabolic syndrome. Obes Rev 13(2):6-13. https://doi.org/10.1111/j.1467789X.2012.01033.x 
41. Abrahamson PE, Gammon MD, Lund MJ, Flagg EW, Porter PL, Stevens J, Swanson CA, Brinton LA, Eley JW, Coates RJ (2006) General and abdominal obesity and survival among young women with breast cancer. Cancer Epidemiol Biomark Prev 15(10):18711877. https://doi.org/10.1158/1055-9965.EPI-06-0356

42. Borugian MJ, Sheps SB, Kim-Sing C, Olivotto IA, Van Patten C, Dunn BP, Coldman AJ, Potter JD, Gallagher RP, Hislop TG (2003) Waist-to-hip ratio and breast cancer mortality. Am J Epidemiol 158(10):963-968

43. Dal Maso L, Zucchetto A, Talamini R, Serraino D, Stocco CF, Vercelli M, Falcini F, Franceschi S, Prospective Analysis of CaseControl Studies on Environmental Factos and Health Study Group (2008) Effect of obesity and other lifestyle factors on mortality in women with breast cancer. Int J Cancer 123(9):2188-2194. https ://doi.org/10.1002/ijc. 23747

44. Tao MH, Shu XO, Ruan ZX, Gao YT, Zheng W (2006) Association of overweight with breast cancer survival. Am J Epidemiol 163(2):101-107. https://doi.org/10.1093/aje/kwj017

45. Pedersen B, Delmar C, Bendtsen MD, Bosaeus I, Carus A, Falkmer U, Groenkjaer M (2017) Changes in weight and body composition among women with breast cancer during and after adjuvant treatment: a prospective follow-up study. Cancer Nurs 40(5):369-376. https://doi.org/10.1097/NCC.000000000000042 6

46. Ellberg C, Olsson H, Jernström H (2018) Current smoking is associated with a larger waist circumference and a more androgenic profile in young healthy women from high-risk breast cancer families. Cancer Causes Control 29(2):243-251. https://doi. org/10.1007/s10552-017-0999-3

47. Persson $\mathrm{M}$, Simonsson $\mathrm{M}$, Markkula $\mathrm{A}$, Rose $\mathrm{C}$, Ingvar C, Jernström H (2016) Impacts of smoking on endocrine treatment response in a prospective breast cancer cohort. Br J Cancer 115(3):382-390. https://doi.org/10.1038/bjc.2016.174

48. Davis SR, Lambrinoudaki I, Lumsden M, Mishra GD, Pal L, Rees M, Santoro N, Simoncini T (2015) Menopause Nat Rev Dis Primers 1:15004. https://doi.org/10.1038/nrdp.2015.4

49. Mullooly M, Yang HP, Falk RT, Nyante SJ, Cora R, Pfeiffer RM, Radisky DC, Visscher DW, Hartmann LC, Carter JM, Degnim AC, Stanczyk FZ, Figueroa JD, Garcia-Closas M, Lissowska J, Troester MA, Hewitt SM, Brinton LA, Sherman ME, Gierach GL (2017) Relationship between crown-like structures and sex-steroid hormones in breast adipose tissue and serum among postmenopausal breast cancer patients. Breast Cancer Res 19(1):8. https:// doi.org/10.1186/s13058-016-0791-4

50. Hollmann M, Runnebaum B, Gerhard I (1997) Impact of waisthip-ratio and body-mass-index on hormonal and metabolic parameters in young, obese women. Int J Obes Relat Metab Disord 21(6):476-483

51. Plymate SR, Hoop RC, Jones RE, Matej LA (1990) Regulation of sex hormone-binding globulin production by growth factors. Metabolism 39(9):967-970

52. Mason C, Xiao L, Duggan C, Imayama I, Foster-Schubert KE, Kong A, Campbell KL, Wang CY, Alfano CM, Blackburn GL, Pollack M, McTiernan A (2013) Effects of dietary weight loss and exercise on insulin-like growth factor-I and insulin-like growth factor-binding protein-3 in postmenopausal women: a randomized controlled trial. Cancer Epidemiol Biomark Prev 22(8):14571463. https://doi.org/10.1158/1055-9965.EPI-13-0337

53. Simonsson M, Söderlind V, Henningson M, Hjertberg M, Rose C, Ingvar C, Jernström H (2013) Coffee prevents early events in tamoxifen-treated breast cancer patients and modulates hormone receptor status. Cancer Causes Control 24(5):929-940. https://doi. org/10.1007/s10552-013-0169-1

54. Aleman JO, Iyengar NM, Walker JM, Milne GL, Da Rosa JC, Liang Y, Giri DD, Zhou XK, Pollak MN, Hudis CA, Breslow JL, Holt PR, Dannenberg AJ (2017) Effects of rapid weight loss on systemic and adipose tissue inflammation and metabolism in obese postmenopausal women. J Endocr Soc 1(6):625-637. https ://doi.org/10.1210/js.2017-00020

55. Dieli-Conwright CM, Lee K, Kiwata JL (2016) Reducing the risk of breast cancer recurrence: an evaluation of the effects and mechanisms of diet and exercise. Curr Breast Cancer Rep 8(3):139-150. https://doi.org/10.1007/s12609-016-0218-3

56. Eaker S, Halmin M, Bellocco R, Bergkvist L, Ahlgren J, Holmberg L, Lambe M, Uppsala Orebro Breast, Cancer G (2009) Social differences in breast cancer survival in relation to patient management within a National Health Care System (Sweden). Int J Cancer 124(1):180-187. https://doi.org/10.1002/ijc.23875

57. Berglund A, Wigertz A, Adolfsson J, Ahlgren J, Fornander T, Warnberg F, Lambe M (2012) Impact of comorbidity on management and mortality in women diagnosed with breast cancer. Breast Cancer Res Treat 135(1):281-289. https://doi.org/10.1007/s1054 9-012-2176-4

Publisher's Note Springer Nature remains neutral with regard to jurisdictional claims in published maps and institutional affiliations. 